\section{TAXATION AND RESEARCH EXPENDITURE}

A

FEATURE of recent reports on industrial research has been the emphasis which has been placed on the influence taxation is capable of exerting upon research expenditure. The Federation of British Industries, for example, has advanced the principle that all expenditure on research and development should be chargeable against revenue, either immediately or over the commercial life of any asset created. This principle was strongly endorsed by the Industrial Research Committee of the Federation, which in its report last autumn referred to the deterrent effect on the expansion of research of any narrow interpretation of what is allowable expenditure for taxation purposes. The London Chamber of Commerce, expressing its agreement with this view, urged further that the cost of pilot plant, as well as of laboratory buildings and equipment, should be made chargeable against equipment. The question has been further examined by the Parliamentary and Scientific Committee, which in a memorandum on Taxation and Research examined the present position and instanced some of the defects of the present system. This memorandum was based on the ideas first that in modern conditions no industry can maintain its competitive position unless it devotes adequate effort and money to scientific and industrial research. This applies with special force to British industry, having regard to the conditions and tasks which will confront it after the War. Secondly, the money required for such research will be substantially greater than in the past. Again, judged by standards in other industrial countries, and quite apart from its own exceptional needs, British industry has in the past devoted far too little effort and money to scientific and industrial research; and lastly, an increase in the productivity of labour, which is one of the main consequences of industrial research, is a vitally important factor in making possible an improvement in wages and social services. The recent debate in the House of Commons on Government provision for research showed that these ideas are widely shared.

The memorandum went on to urge that every impediment to the undertaking of scientific and industrial research by British industry should be removed and inducements provided to stimulate progress. In particular, the memorandum recommended that the law relating to the taxation of profits should be amended so as to recognize the principle that all expenses incurred on research and development are allowable as deduction from taxable profits, with the corollary that receipts from a lease or sale of discoveries should be brought into taxable profits. Expenditure on research which creates a tangible asset with a measurable life, and expenditure on the purchase of patents and processes, should be similarly allowable over a period of years. All other expenditure should be allowable in the year when it is spent. No distinction should be made between pure research and applied research and development. A special writing-off allowance on capital assets provided solely for research purposes was also suggested, as well as the increase of depreciation rates for industrial buildings and plant to include obsolescence by an arbitrary addition to the rates allowed for wear and tear.

Sir John Anderson went far to meet these proposals in his Budget speech, which may well be regarded as something of a landmark in this respect. Recognizing first the supreme importance of appropriate allowances for capital expenditure in relation to reconstruction to enable British industry to meet the post-war challenge, he proposed a special allowance of 20 per cent of the cost of new plant and machinery, and as a part of post-war policy that the obsolescence allowance should be given when plant and machinery are scrapped, whether the particular piece of plant or machinery is replaced or not. With regard to buildings such as factories and buildings associated with them for welfare purposes or storage, he proposed an annual depreciation allowance of 2 per cent with an initial allowance of 10 per cent as an immediate instalment.

Referring to scientific research, the Chancellor of the Exchequer believes there is a case for modifying the distinction drawn for income-tax purposes between capital and revenue expenditure on research. $\mathrm{He}$ therefore proposes that any research expenditure of a capital nature, including expenditure on laboratory buildings, plant and machinery, should be allowed for a period of five years, or for the life of the asset, whichever is the shorter, as a deduction from profit for income-tax purposes. Further, any payment, whether for capital purposes or not, made by a trader to a central research body approved by the Department of Scientific and Industrial Research, should be allowed as and when made as a deduction in computing the profits of the concern.

Sir John Anderson, after observing that we should not depreciate our own efforts in the field of research, went beyond these proposals to relieve from taxation funds devoted to research, and expressed the hope that there would be much wider pooling of ideas in the field of research, and that the industrial research worker should be encouraged to regard himself not only as a servant of the organization which pays him, but also as a contributor to the sum total of available knowledge. Referring to chemical industry and the extraction of products from oil and coal, where plastics is only one of the fields opened up, he said that there should be no obstacle placed in the way of chemical industry in obtaining raw materials from oil. He was not prepared to place scientific proposals before Parliament at the moment, but proposed to arrange with the Minister of Fuel and Power for an inquiry to supply the data required for specific proposals.

Following so swiftly on the debate in the House of Commons on Sir Granville Gibson's motion on April 19 (see p. 539), the Chancellor's speech should give the liveliest satisfaction to scientific workers. His speech, no less than his proposals, leave no room for doubt as to the importance the Government attaches to research, or its appreciation of the contribution scientific workers have made to the war effort. That 
such proposals and recognition should find so prominent a place in the Budget speech affords firm ground for the hope that scientific workers will be given a full opportunity to play their part in reconstruction, and that the Government is determined to establish the conditions in which scientific and industrial research may make the largest possible contribution to the progress and well-being of the nation.

\section{RHEOLOGY: PRACTICAL AND THEORETICAL}

Ten Lectures on Theoretical Rheology

By Dr. Markus Reiner. Pp. iv + 164. (Jerusalem : Rubin Mass ; London: H. K. Lewis and Co., Ltd., 1943.) 22s. $6 d$. net.

\section{A Survey of General and Applied Rheology}

By Dr. G. W. Scott Blair. Pp. xvi+196. (London : Sir Isaac Pitman and Sons, Ltd., 1944.) 18s. net.

$\mathrm{R}$ HEOLOGY probably owes much of its appeal to the fact that it has not yet developed into a fully established science with a generally accepted subject-matter and method of treatment. The study of the "flow and deformation of matter" might include almost anything in Nature, and indeed there are few industries in which problems essentially rheological in character do not arise. These problems frequently have to be attacked by chemists, physicists or engineers whose training has provided them with only a very meagre basis on which to work, and the appearance of two books on rheology by two of the best-known pioneers in this field will be especially welcome to them.

The two authors approach their subject at very different angles. Dr. Reiner, taking the point of view of the mathematical engineer, develops his subject by methods of the kind with which we have become familiar in the classical theory of elasticity. He says, in effect, "These equations represent possible types of behaviour of matter; let us see whether we can find materials which behave accordingly". Dr. Scott Blair, on the other hand, sets out from the experimentally observed rheological phenomena (of which he possesses an encyclopædic knowledge), tries to find equations to represent the data, and hopes that an explanation may emerge.

Dr. Scott Blair shows us that the essence of a rheological investigation is the determination of the relation between the three variables, stress, strain and time. Starting from a consideration of the two extreme 'ideal' materials, the Hookean elastic solid and the Newtonian viscous liquid, he leads up to the discussion of those more complex materials (which are the special concern of rheology) for which both the amount of strain and rate of straining vary with time, under constant applied stress. Such materials combine some of the characteristies of both the solid and liquid states. Altogether there are at least nine main types of deformation (or flow), which are presented in the form of a table, but this is not considered to be exhaustive. Thixotropy, dilatancy, plasticity, false body and a number of other rheological phenomena are discussed in detail, and particular attention is paid to the question of definition of the terms employed. The book contains a full discussion of the significant information to be sought in a rheological investigation, and a critical examination of the experimental methods available. A valuable feature is the inclusion of a comprehensive collection of references, carefully arranged and annotated. (But why Roman numerals for volume numbers?)

In the second part of the book Dr. Scott Blair deals with a subject which has so far received comparatively little àttention by rheologists, namely, the very important practical question of the relation between physical measurements and psychological judgments. The problem confronting the rheologist in industry is to find quantitative methods of assessing properties which the skilled craftsman is in the habit of judging by thumb-and-finger methods. The concepts entering into the judgment are usually mixed, and seldom conseiously appreciated. The situation is very well illustrated by the concept of 'firmness', which has been the subject of a special investigation by the author and his collaborators. From the results of this investigation one is forced to conclude that the concept of firmness is not based on a mental analysis of perceptions into concepts of the kind with which ordinary physics deals, such as, for example, average applied force or total strain. The judgment appears to be a direct reaction to the total situation, in which all the relevant components are appreciated as a single integrated pattern or Gestalt. Here one is in danger of becoming involved in the philosophical mystery of the relation between the conscious perceiving mind and the external (?) perceived universe. But without going so far, one must recognize that Dr. Scott Blair has brought out the rather fundamental difficulty of what might appear at first sight to be a straightforward problem in rheology, and this presentation of his unique experiments will be generally welcomed.

Dr. Reiner begins his "Lectures" with an analysis of stresses and strains, using tensor notation. $\mathrm{He}$ develops the conception of a general rheological equation relating stress and strain and the timederivatives of these variables. By suitable choice of the terms of this equation, special cases are obtained which represent possible types of rheological behaviour. Arranging the types in order, we have at one end the Euclid (incompressible and undeformable) solid. Then follow the Hookean (ordinary elastic) solid, and the Kelvin (viscous) solid, in which the elastic deformation is subject to a time lag. At the other extremity we have the Pascalian (incompressible non-viscous) liquid, the Newtonian (viscous) liquid, and the Maxwell (elastic) liquid, in which the stress decays with time. The properties of these types are discussed, and compared with actual materials. The intermediate region contains the more complex types, some of which are discussed in detail. The table may be compared with the rather similar table of deformations given in Dr. Scott Blair's book.

A number of special problems are considered, including, in particular, the theory of breaking. It is shown that a Kelvin solid breaks when the strain reaches a given value, while in a Maxwell liquid failure occurs at a critical value of stress.

It would appear that in respect of purely elastic strains, the tensor methods used in this book are applicable only when the strains are small. Many rheologists would like to know what methods to apply in the case of large deformations.

Both the works under review, which are in a sense complementary, should be studied by all who are interested in rheology. $\quad$ L. R. G. TreloaR. 